\title{
Green bond as a new determinant of sustainable green financing, energy efficiency investment, and economic growth: a global perspective
}

\author{
Yiyi Ning ${ }^{1} \cdot$ Jacob Cherian $^{2} \cdot$ Muhammad Safdar Sial $^{3} \cdot$ Susana Álvarez-Otero ${ }^{4} \cdot$ Ubaldo Comite $^{5} \cdot$ Malik Zia-Ud-Din $^{6}$
}

Received: 7 August 2021 / Accepted: 28 December 2021

(c) The Author(s), under exclusive licence to Springer-Verlag GmbH Germany, part of Springer Nature 2022

\begin{abstract}
The purpose of the study is to test the role of green bond financing on energy efficiency investment and economic growth. To achieve the study objective, fuzzy decision-making modeling technique is applied. The results revealed that bank loans are now the main source of financing for energy efficiency projects. Project-based financing might be replaced with Energy Performance Contracts (EPC) warranting energy efficiency investment. Moreover, green banks invest both public and private funds in energy efficiency promoting economic growth. The usage of green bonds for financing environmentally beneficial projects or companies is limitless. Providing for screening energy efficiency investment proposals with small payback hurdle rates might have large opportunity costs. Green bonds can be used to remove the financing barriers for green finance and sustainability tool. On this, study provides policy implications to key stakeholders; if suggested policy suggestions implemented successfully, these would help to enhance scope of green bond financing to uplift energy efficiency financing and green growth successfully.
\end{abstract}

Keywords Green bonds · Energy efficiency investment · Economic growth · Energy financing · Environmental efficiency

\section{Introduction}

To reach the $1.5^{\circ} \mathrm{C}$ target, a drastic adjustment in investment patterns is necessary (McCollum et al. 2018). This transformation will need more government programs encouraging

Responsible Editor: Philippe Garrigues

Muhammad Safdar Sial

safdarsial@comsats.edu.pk

Yiyi Ning

yiyining011@foxmail.com

Jacob Cherian

jacob.cherian@adu.ac.ae

Susana Álvarez-Otero

saotero@uniovi.es

Ubaldo Comite

u.comite@unifortunato.eu

Malik Zia-Ud-Din

malikziaudin@yahoo.com

1 Wuhan ecological environment investment and development Group Co.Ltd, Wuhan City 430000,

People's Republic of China the issuance of green bonds (Baraua and Chiesa, 2019). Generic bonds may be used to support any legal project, but revenues from green bonds may only be used to support initiatives that mitigate climate change, conserve natural resources, or conserve biodiversity (Chugan, Mungra

2 College of Business, Abu Dhabi University, P.O. Box 59911, Abu Dhabi, United Arab Emirates

3 Department of Management Sciences, COMSATS University Islamabad (CUI), Islamabad 44000, Pakistan

4 Department of Business Administration, Faculty of Economics and Business, University of Oviedo, 33003 Oviedo, Spain

5 Department of Business Sciences, University Giustino Fortunato, 82100 Benevento, Italy

6 Department of Law, Islamia University, Bahawalpur 63100, Pakistan 
and Mehta, 2017). In the meantime, however, dealing with Southeast Asia's growing energy demand is essential for attaining future energy needs. To spur green finance, a large change in investment patterns is required ( $\mathrm{Li}$ et al., 2021). Green finance initiatives including green bond standards, green bond grant programs, and sovereign green bonds are being used increasingly across Asia. Green bonds have been rising in popularity throughout Asia and the globe as an option to fund low-carbon developments (Durrani et al., 2020). The green bond market has expanded from $\$ 3.4$ billion in 2012 to $\$ 156$ billion in 2017. Europe's public and private lenders established the first green bonds in 2007 and 2008. In 2015, China joined the green bond market, making it the world's biggest issuer of green bonds.

China issued $\$ 34$ billion and $\$ 31$ billion in green bonds in 2016 and 2017, respectively. Green bond award schemes resulted in increased green bond issuance (Bracking. 2015). Although green bond grant programs were not always utilized to promote decarburization, they were more typically utilized to fund renewable energy or energy efficiency improvements elsewhere (Linton et al., 2021). Policy suggestions are presented based on the evaluations of green bond grant schemes. Only projects in the nation where the bonds were issued should be eligible for green bond grant programs, and projects that require refinancing must also be permitted in these programs (Gibon et al., 2020). The challenges of climate change have seriously upraised vital questions about the stability and the growth of the financial sector's contribution in converting the polluted economies into green economies (Alemzero et al., 2021). The global financial crises also pointed out serious questions about environmental pollution and green future of the economies (Iqbal et al., 2021a, b). Such questions boosted the attentions of theorists and policymakers of financial sector to act as a catalyst in resolving such environmental issues through green financing. Considering such issues, modern time also raised a call to unseal the green financing to address the carbon-neutralization issues through financial sectors ( $\mathrm{Li}$ et al., 2021).

More so, recent study intends to suggest the policy implications on green growth and green energy economy through green financing, for they policymakers (Gao et al., 2021). For this, we came up with the argument that green financing is mandatory option for the green growth of any economy (Iqbal et al., 2021a, b). However, recent study attempted to investigate the available resources of green bonds used to estimate the green growth in speedily emergent markets. For this purpose, green financing through green bonds is key to green growth to reduce the environmental defects and pollution (Anh Tu et al., 2021). Hence, this high tended scope of green bonds warranted a need for a close investigation suggesting the most fitting solutions about their problems, potential chances, and environmental benefits (Green and
Sustainable Finance, 2021). Extending to it, green financing through green bonds has become a vital way forward to finance for the environment related issues to clean (Anht Tu et al., 2021). Such financing technique is modern tool giving way to the global world for financing and managing environment and growth-related aspects helping economies to sustain and grow on green basis. In short, green financing through green financing is modern solution to the globe for green development (Azhgaliyeva et al., 2020). One of the obstacles for green development is how to effectively finance green projects from the public, private, and not-for-profit sectors (Linton et al., 2021). This argument unlocked the new avenues of financing and holds the potential to replace traditional modes of financing, such as government subsidies and public financing (Iqbal et al., 2021a, b).

Importantly, there is a dire need to develop the market mechanism that can pool financial markets more effectively to fund green projects (Li et al., 2021; Anh Tu et al., 2021). Green bonds are latest instruments of green financing. Previous studies highlighted that green bonds are less studied in the domain of energy efficiency systems and warranted to investigate to add up in the body of knowledge (Devine and McCollum, 2021). To the best of our reading, none of study is found studying green bonds, energy efficiency investment and economic growth, and presenting way forwards to manage (Nenonen et al., 2019). However, there is a need to test the role of green bond financing on energy efficiency investment enhancing green economic growth to present a policy implication controlling the study phenomenon (Russo et al., 2021). Hence, the objective of the study is to test this novel connection between these constructs and present best possible solutions to the associated stakeholders. To fill this need, different alternative "clean and green" initiatives like renewable energy usage are being practiced on worldwide basis. According to Bloomberg report of 2017, net value of renewable energy was realized upto $\$ 279.8$ billion and this is sufficient investment through traditional sources of financing.

In contrast to it, Reboredo (2018) discussed and green bonds as modern tool of financing for financial markets and proved co-movement, price effects, and diversification. In addition, Yoshino et al. (2019) presented the gaps persisting in the field of green financing and suggested to study in the context of green energy financing. Endorsing the suggestion, recent study covers this gap and advances the theory and practice by taking a step toward sustainable green energy economy. Attribute-wise green bonds are similar to traditional bonds carrying a par-value with a stated rate of return along with a certain time frame. Notably, a sum of stated amount would be generated from financial markets by the amount of notional principal along with a coupon payment, under a certain period of time. According to UNDP (2018), a bond issuer has to produce adequate fund flow to clear notional payment 
and interest rate payment. On the basis of term structure, green bonds are aligned with conventional bonds but with sole differentiation-purpose of the bond's issuance. Extending it, green bonds intend to for climate change mitigation financing and other environment related activities, around the globe. It is inferred from the findings that various developed economies invested \$253 billion for climate change mitigation through green financing during FY 2017-2018, under Climate Policy Initiative (CPI, 2019). Undoubtedly, this amount has contributed in raising green growth in economies.

From this amount of green capital, $\$ 33$ billion were financed for energy efficiency, $\$ 94$ billion for transport sector, $\$ 58$ billion for the renewable energy sources. This becomes evident that many countries are striving for clean future by issuing green bonds (see Fig. 1). By this, the CPI report shows a significant variability of green financing in energy sector. The growth prospect of green financing is infinite. According to IEA (2019), around $\$ 3.95$ trillion US dollars are forecasted by the analysts for green bonds to clean the environment and finance energy sector by the wake of fiscal year 2050. In recent study, we attempt to present the solutions for green growth, for which green bonds are mandatory sources of adoption (Gianfrate and Peri, 2019). As cited before, green growth has significant role in boosting national economic activities (Draksaite, Kazauskiene and Melnyk, 2018). Our study contributed by advancing the readings on green financing and green energy economy by prioritizing the policy initiatives. Thus, this study has three key research objectives. First, it seeks to advance the green finance notion by studying in energy economy side. Second, it attempts to resolve the social, economic, and political barriers reversing green financing and green growth. Finally, it presents the possible way forwards for maximum integration of renewable or carbon clean energy sources through green financing.

\section{Green bond and green growth possibility}

Green bond (GB) is the concept of World Bank primarily introduced in late 2010, raised to reverse high carbon emission and o mitigate the climate changes (Zhou and Cui, 2019). According to GB fundmentals, projects are keenly assessed and are financed through green bonds to commence green energy (Maltais and Nykvist, 2020), boost green energy intensity for communities (Tnag and Zhang, 2020), reducing waste disposal (Wisniewski and Zielinski, 2019), environment friendly transportation and sustainable climate change management (Flammer, 2021). Nature wise green bonds are like debt financing tool same as conventional debt instrument. These bonds are also traded with and without interest rate, along with different provisions on debt repayment, and recourse or non-recourse of issuing organizations. Thus, GB is much supportive for key stakeholders, such as, investors, traders, and community. For investors, GB trading in particular stock exchange will be provided alternative and new option for portfolio optimization and diversification, by levering the capital invested through this latest risk-free security (Bwowne, 1995). For traders, GBs will be new tool to trade, earn, and manage the fund flow system of the primary and secondary market, by diversifying the unsystematic risk.

Curtaining the rising future of greening the growth and economy, the GB market has potential accelerate both in terms of quantity and quality. Therefore, a significant role of GB is expected supporting to make markets as efficient, and alternatively, such bonds hold the ability to serve the society in terms of societal benefits like mitigating carbon emission by providing the capital support to develop and sustained climate friendly projects (Taghizadeh-Hesary and Yoshino, 2019), and to subsidize in green energy economy. The idea of green growth was presented as a core theme at the Rio +20 conference in late 2012, and was aimed to discuss key outcomes for future planning as per the united
Fig. 1 Country-wise issued capital through green bonds from FY 2010 to 2020

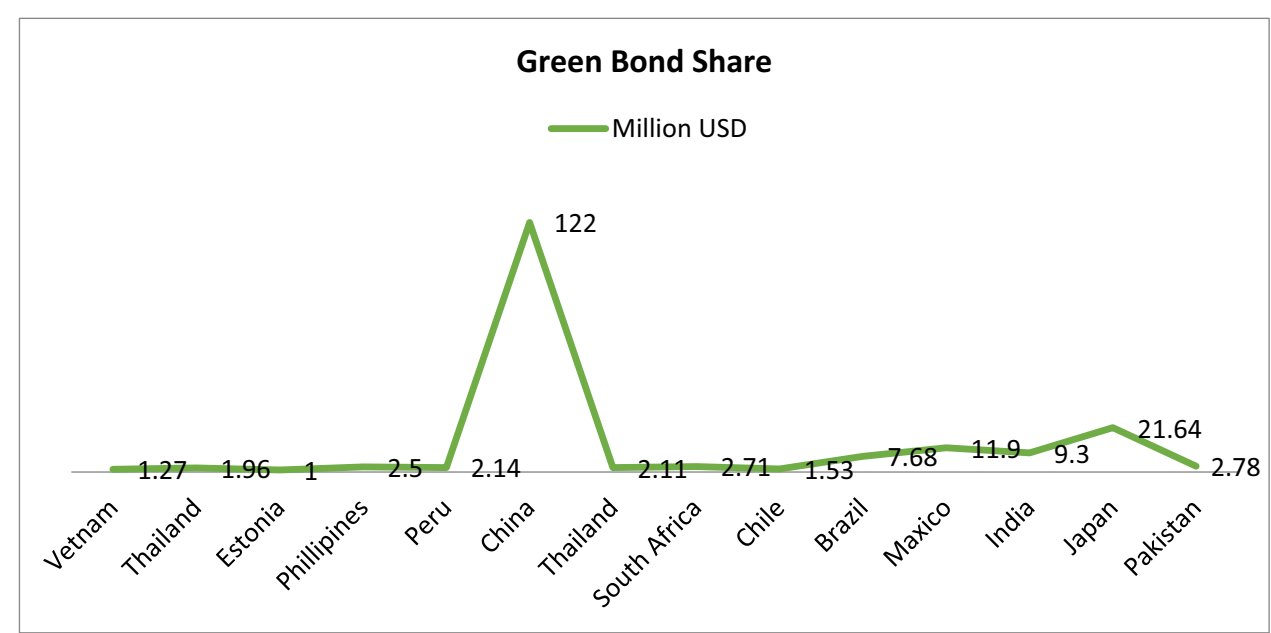


nations future agenda (Taghizadeh-Hesary et al., 2019), from this discussion two novel terms (e.g. green growth and green economy), were introduced. From here, green growth has increased significant importance about climate change control (Hickel and Kallis, 2020). Moreover, green growth has ability to contribute significantly in economic indicators, such as gross national and gross domestic product with an environment friendly approach (Yoshino et al., 2019). Predominetly, this linkage is theoretically supported by the green growth theory (Iqbal et al. 2021a, b). Such growth accelerates demand of energy and hinders the use of renewable energy due to tight and obsolete industrial processes.

Therefore, there is need to revise industrial processes and introduce alternative sources of financing, such as green bonds for the green future of industrial units and small and medium projects, and ultimately, this raises the growth of the economies in green way. The latest studies on green growth are gaining significant attention for further exploration and standing on the shoulders of the green growth giants' recent study also aims to investigate green growth in the context of green energy economy (GEE) by assessing the role of green bonds. It is noted that several global organizations and many published studies are directed to strive for green growth by addressing the issues with low-carbon energy technologies to build a GEE. According to OECD, (2011) to extend the economic growth and environmental stability, green financing through green financing instrument has a pivotal role in determining environmental efficiency, economic growth under green growth systems (p. 9). More so, the conference of World Bank held in (2012) that green growth contributes in different ways, such as raising production function, raising production efficiency toward production frontier line, stimulating economic environment under period of crises and innovation through creative solutions (p. 29). This has shown viable nexus between green growth and green energy economy and much more working is still needed to prove this possible nexus. Therefore, recent study uncovered this topic to prove this possibility of nexus and presented different policies for key public stakeholders, as related stakeholders are found as aligned with a specific degree of agreeableness or disagreement about green growth (Le et al., 219).

Interestingly, it emerges multiple aspects including financing to mitigate energy-related risks, unemployment reduction factors, pooling economic activities through diversification and boosting environmental economics through affordability (Anh Tu et al., 2021). On this, Yoshino et al. (2021) extended the argument that environment and economics have a very close tie, as pollution mitigation reduces climate change and effective climate system fuels economic growth under green parameters. Moreover, several environmental effects of carbon-energy technology are suggested to follow for these solutions ( $\mathrm{Li}$ et al. 2020). From a social point of view, a GEE aims to improve human welfare, reduce energy-related risks, social inequalities, and poverty; promote intergenerational equality; and foster new opportunities for human development (Iqbal et al., 2021a, b). The role of policy-driven low-carbon energy technologies is a horizontal element that is critical in any GEE transition (Iqbal et al., 2021a, b; Alemzero et al., 2021).

\section{Data and methodology}

\section{Energy efficiency investment in practice}

The available research on real capital budgeting decisionmaking includes significant surveys of corporate finance officers (CFOs). Based on the survey results, it seems that payback analysis is employed more often than NPV or IRR analysis advocated by the financial academic community. Investment criteria such as IRR, NPV, and PB are utilized by most businesses for investment research. Only $4 \%$ of organizations employed one investment criterion with all four. Twenty-eight percent utilized two investing criteria, 32\% used three, and 36\% utilized four. Only 5\% of the enterprises did not employ PB in their investment analysis. According to statistics published by Graham and Harvey (2001), over 90\% of enterprises who use either NPV or IRR also employ PB for investment analysis. The use of PB is not on the wane in capital planning; according to Sachs et al. (2019), payback analysis is an easy-to-use and straightforward approach to determine the number of years an investment will take to cover its costs. The most evident shortcoming of payback analysis is the inability to tell short and long-term investments apart. Firm level payback policies are by definition conservative since "bad" judgments may be mitigated by conservative assumptions. As a consequence, investments that were successful because of more thorough investment information are rejected using payback analysis. Given the complexities highlighted in the energy paradox literature, most organizations use basic payback rule-of-thumb decision-rules to assess energy efficiency initiatives. The process uses reduced decision rules that align with Nelson and Winter's (1982) procedural rationality, which postulates firmlevel procedural rules as a method to integrate firm-level learning and decision-making continuity. Other behavioral characteristics, such as loss aversion, may affect the decision process at the individual agent level.

\section{DDF approach and green financing indicator}

For the measurement of the energy-related modeling and green financing, radial distance function (DDF) is widely used. DDF modeling is one of the finest approaches estimating the model fit on the basis of output (e.g. good or bad). DDF modeling helps researchers to determine the efficiency 
of the study modeling which compares and contrast the performance through decision making unit (DMU). The study has developed the green growth index (GGI) and used DDF approach to test the nexus. In GGI, energy productivity, material productivity, share of renewable energy consumption, carbon productivity, portion of land area covered by forest and share of GDP from service sector were the proxies taken to measure and operationalize. Suppose that every decision-making unit (DMU) utilizes $m$ number of inputs $x \in R^{m}$ to produce $\mathrm{r}$ number of expected desirable outputs $y \in R^{r}$ and $f$ number of undesirable output (green growth index) $u \in R^{f}$. Endorsing Baniya, Giurco and Kelly (2020), GGI is constructed and different production functions for inputs and outputs are also developed, as given below,

$P(x)=\{(x, y, u)\}: x$ canproduceyand $u$

where $P(x)$ is necessary to satisfy the standard axiom of green growth theory and theory of green economics. More so, null and alternate assumptions for the imposition of $P(x)$ for the green growth toward green-energy economy were also incorporated. For this, dimensions of green financing through green bonds were also endorsed and considered. The null-jointness and weak disposability assumption assumptions are expressed as follows:

(1) If $(x, y, u) \in P(x)$ and $0 \leq \theta \leq 1$ then $(x, \theta y, \theta u) \in P(x)$

and.

(2) If $(x, y, u) \in P(x)$ and $u=0$ then $y=0$.

Considering such function, directionality of an output function is also very important to consider for the problem handling often caused by simultaneous rise or fall in output functions. For example, let $d=\left(d_{y}, d_{u}\right)$, since it has been determined that the radial efficiency measurement of DDF is effective in measuring green growth. Färe et al. (2007) proposed radial DDF, which is selected in this study. The output directional distance function is presented as:

$\vec{D}\left(x, y, u ; d_{y}, d_{u}\right)=\max \left\{\beta:\left(y+\beta d_{y}, u-\beta d_{u}\right) \epsilon P(x)\right\}$

Usually, parametric and non-parametric DDF models of DEA are used to infer DDF approach. Recent study considered to estimate the green growth through green bonds. Therefore, parametric DEA approach is considered to assess the technical efficiency of study model. Using parametric approach, the following DEA type model is used to calculate the technical efficiency of the k-th DMU in each high-energy industry and energy-economy:

$\vec{D}\left(x_{k}, y_{k}, b_{k} ; d_{y}, d_{u}\right)=\max \beta_{k}(3)$

S. $t$

$$
\sum_{j=1}^{j} x_{m j} \lambda_{j} \leq x_{m k}(m=1,2,3, \ldots, M)(4)
$$

$\sum_{j=1}^{j} y_{r j} \lambda_{j} \geq y_{r k}+\beta y_{r k}(r=1,2, \ldots, R(5)$

$\sum_{j=1}^{j} u_{f j} \lambda_{j}=u_{f k}-\beta u_{f k}(f=1,2,3, \ldots, F)(6)$

$\sum_{j=1}^{j} \lambda_{j}=1(j=1,2,3, \ldots, J)(7)$

$\lambda_{j} \geq 0(j=1,2,3, \ldots, J), 1 \geq \beta \geq 0(8)$

where among them, $x_{m j}, y_{r j}$, and $u_{f j}$ represent the mth input of the jth DMU, the rth expected output and the fth undesired output. $\lambda_{j}$ is the intensity variable. $\lambda_{j}$ is the weight assigned to DMU $j$ when constructing the production possibility boundary? $J, M, R$, and $F$ are the number of DMU, input, expected output, and bad output. $\beta_{k}$ represents a feasible extension of DMU $k$. The objective function "maximum $\beta_{k}$ " refers to the maximum ratio of DMU $k$ 's ideal output expansion and bad output contraction. The weak disposability assumption is applied in this study, which can be reflected by the constraint $\left\{\sum_{j=1}^{j} u_{f j} \lambda_{j}=u_{f k}-\beta u_{f k}\right\}$. However, to advance the theory and practice of green financing by contributing in green energy economy the input variable $x$ includes green bond prices (e.g., a measure of green financing) having one indicator, and the output function includes 6 functions of green energy growth. The study applied following model to acquire green growth index (GGI) of the sample countries of South Asia $k$ :

$G E P I=1-\beta_{k}(9)$

If $\beta_{k}$ equals zero, it means BRI countries $k \mathrm{GGI}$ is equal to 1 which is an efficient country regarding the green economic country and it is located at the efficient frontier. However, in the case of $\beta_{k}$ positive specifies the level of inefficiency of DMU $k$. Mathematically, if its original desirable gross output is $\mathrm{y}_{k}$, then its optimal gross output is $\left(1-\beta_{k}\right) \mathrm{y}_{k}$. Table 1 shows the attributes and types of green bond.

\section{Establishing assessment criteria for study indicators}

Due to the ambiguous nature of decision-making difficulties, individuals are often unable to accurately express their preferences in many real-world circumstances. For the first time, Zadeh (1965) proposed the fuzzy set theory, which was directed toward rationality in the face of 
Table 1 Attributes and types of green bonds

\begin{tabular}{ll}
\hline Green bond type & Characteristics \\
\hline Use-of-proceeds bond & Proceeds are earmarked for green projects in the issuer's portfolio \\
Use-of-proceeds revenue bond & Recourse is to the issuer's entire balance sheet \\
& Proceeds are earmarked for green projects in the issuer's portfolio \\
& Recourse is limited to an issuer's pledged revenue streams, not their entire balance sheet \\
Project bond & Proceeds are earmarked for a specific project or group of projects \\
& Recourse is limited to those project(s) assets and balance sheet \\
Securitized bond & Bond is collateralized by one or more revenue generating green projects e.g. loan repay- \\
& ments on rooftop solar packages \\
& Project revenue is used to repay the bond and recourse is limited to the collateralized assets
\end{tabular}

Table 2 Fuzzy expressions of linguistic terms

\begin{tabular}{ll}
\hline Verbal scale & Fuzzy number \\
\hline Equally important & $(1,1,1)$ \\
Intermediate & $(1,2,3)$ \\
Weak & $(2,3,4)$ \\
Intermediate & $(3,4,5)$ \\
Strong & $(4,5,6)$ \\
Intermediate & $(5,6,7)$ \\
Very strong & $(6,7,8)$ \\
Intermediate & $(7,8,9)$ \\
Absolutely important & $(9,9,9)$ \\
\hline
\end{tabular}

ambiguity in human reasoning. Following the Besikci et al. (2016) The FAHP approach has been chosen because experts' opinions will be utilized to weigh the energy efficiency investment, economic growth, and green bonds as new determinant for green finance' data in this investigation. Extending to it, the analytic hierarchy process (AHP) is frequently employed to address unstructured issues in a broad range of academic disciplines, including economics and politics (Salvia et al., 2019; Nagesha and Balachandra, 2006). However, this approach is often criticized for its inability to give accurate numerical values to the comparison judgments and its ineffectiveness when used to confusing circumstances. Some academics have coupled the Fuzzy theory with the AHP approach to handle fuzzy comparison matrices since standard AHP cannot give enough assistance in the very confusing reality (Kablan, 2004). Table 2 shows the Fuzzy expression of linguistic terms.

In this study, the first-level indicators were chosen based on 12 expert professors through email and shared questionnaires to get the response on recent study agenda. Thus, questionnaire-based responses were used and then coded for analysis in this study (see Table 1). Using FAHP, we identified green innovation for renewable energy sources as a main hurdle in getting the feedback through questionnaire.

\section{Empirical estimation structure}

The study considered FAHP and FTOPSIS hybrid systems of operational research, as shown in Fig. 1. In this figure, the analysis of the study is listed with key consideration. Correspondingly, the motivation of this section is aligned with the study objectives; to locate the issues of green bonds adoption in small and medium-sized companies. For this purpose, authors contacted 12 expert professors through email and shared questionnaires to get the response on recent study agenda. Using FAHP, we identified green innovation for renewable energy sources as a main hurdle in getting the feedback through questionnaire. This hurdle was further confirmed in FTOPSIS analysis.

\section{FAHP approaches}

To explain and resolve compounded and inclusive decision-related issues, analytical hierarchy (AHP) approach is one of the best solutions (Solangi et al., 2019a). The study future extended that AHP is one of the fine approaches to assess competency of model and stability for efficient decision making. Let a matrix be $H=\left(h_{i j}\right)_{n \times m}$. Let a fuzzy number be $F_{i j}=\left(a_{i j}, b_{i j}, c_{i j}\right)$; a fuzzy number $\tilde{\mathrm{a}}$ is evaluated through a trio $X=(x, y, z)$ whereas the role of association quantity in fuzzy (TFN) is well-defined as follows,

$\mu_{L}(L)=\left\{\begin{array}{c}0, L<1 \\ \frac{L-L}{M-L} i f L \leq L \leq M \\ \frac{N-L}{N-M} i f M \leq L \leq N \\ 0, x>0\end{array}\right\}$

Similarly, there are some other integers that can be taken to measure study intend through FAHP by using AHP (Kim and Chung, 2013). AHP approach is further categorized into different steps: 
Phase I. Plan a best criteria for better decisions and decision finalization by representing with $\{a 1, a 2, \ldots, a n\}$. After this, develop fuzzy indicators for performance and fuzzy weight matrix as shown below,

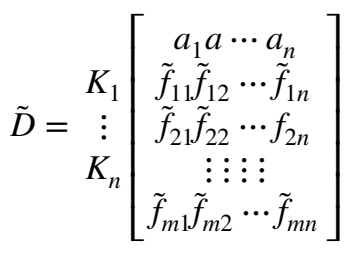

$\tilde{W}=\left(w_{1}, w_{2}, w_{3}\right), \sum_{j=1}^{n} w_{j}=1$

whereas $K_{i}$ indicated substituted options like $i$, i.e., $\mathrm{i}=(1,2,3, \ldots, \mathrm{m}) ; a_{j}$ stipulates deliberated choices $O_{i}$ concerning the principles $C_{j}$; and $\tilde{W}_{j}$ characterize the weight of fuzzy amount for each measures. Therefore, TFN can be quantified by $\tilde{f}_{i j}=\left(l_{i j}, m, n_{i j}\right)$.

Phase II. Define the unsurpassed and nastiest conditions.

$\tilde{f}_{i}^{+}=\max _{j} \tilde{f}_{i j}, \tilde{f}_{i}^{-}=\min _{j} \tilde{f}_{i j}$ for $i \in l^{b}$

$\tilde{f}_{i}^{+}=\min _{j} \tilde{f}_{i j}, \tilde{f}_{i}^{-}=\max _{j} \tilde{f}_{i j}$ for $i \in l^{c}(7)$.

Phase III. Estimate the loadings of normall decision matric $\tilde{D M} \tilde{M}_{i j}$

$$
\begin{aligned}
& \tilde{D M}_{i j}=\frac{\tilde{f}_{i}^{+}(-) \tilde{f}_{i j}}{n_{i}^{+}-l_{i}^{-}} \text {for } i \in l^{b} \\
& \tilde{D M_{i j}}=\frac{\tilde{f}_{i j}^{(}() f_{i}^{+}}{n_{i}^{-}-l_{i}^{+}} \text {for } i \in l^{c}(8) .
\end{aligned}
$$

Above all, a best system of fuzzy decision making is a key source to determine the nexus between the constructs of the study. For this, a vector entitled with "to others" is a best fit and considered as the priority parameter related to the fuzzy standards denominated as: $X Y=(X 1, X 2, \ldots, X n)$, where $X j$ signifies a preeminent principle $X$ which is improved than the standard $j$. In this case, $X 2=1$.

Phase IV. According to fuzzy modeling, the worst criteria are ranked from 1 to 9 respectively. For other than worst criteria, fuzzy vectors are denominated with $Z m=(x 1 z, x 2 z, \ldots x n z)$. By this, the constructs are measured through $\tilde{p}_{j}=\left(\tilde{p}_{j}^{x}, \tilde{p}_{j}^{y}, \tilde{p}_{j}^{z}\right)$ and $\tilde{Q}_{j}=\left(\tilde{Q}_{j}^{x}, \tilde{Q}_{j}^{y}, \tilde{Q}_{j}^{z}\right)$ :

$$
\begin{aligned}
& \tilde{P}_{j}=\sum_{i=1}^{n} \tilde{Y}_{i}(\times) \tilde{D M}{ }_{i j} \\
& \tilde{Q}_{j}=\max _{i} \tilde{y}_{i}(\times) \tilde{D M}_{i j} \\
& S E V_{i}=\sum_{j=1}^{m} F_{i j} \otimes\left[\sum_{i=1}^{n} \sum_{j=1}^{m} F_{i j}\right]^{-1}
\end{aligned}
$$

s.t $\sum_{j=1}^{m} F_{i j}=\left(\sum_{j=1}^{m} a_{i j}, \sum_{j=1}^{m} b_{i j}, \sum_{j=1}^{m} c_{i j}\right)$ for $i=1,2,3,4,5, \ldots, n$

$\sum_{i=1}^{n} \sum_{j=1}^{m} F_{i j}=\left(\sum_{i=1}^{n} \sum_{j=1}^{m} a_{i j}, \sum_{i=1}^{n} \sum_{j=1}^{m} b_{i j}, \sum_{i=1}^{n} \sum_{j=1}^{m} c_{i j}\right)$

$\left[\sum_{i=1}^{n} \sum_{j=1}^{m} F_{i j}\right]^{-1}=\left(\frac{1}{\sum_{i=1}^{n} \sum_{j=1}^{m} c_{i j}}, \frac{1}{\sum_{i=1}^{n} \sum_{j=1}^{m} b_{i j}}, \frac{1}{\sum_{i=1}^{n} \sum_{j=1}^{m} a_{i j}}\right)$

Flight is consistent while displays, where $W$ is a nonfuzzy weight.

$W=\left(u\left(J_{1}\right), u\left(J_{2}\right), u^{\prime}\left(J_{3}\right), \ldots, u\left(J_{n}\right)\right)^{T}$

\section{FTOPSIS technique}

To estimate the energy-environment-economic losses and to cover these losses through green financing, TOPSIS estimation technique is one of the fine recommended tools supporting regulatory standards with the help of green financing (Mohsin et al., 2019). It is evident that the green financing is key to green growth and still warrants to estimate the system under green bonds, for which TOPSIS technique is considered to apply to estimate this nexus between green bonds and green growth in more sophisticated way. According to Boran (2017), this technique was introduced by the Yan and Yoon in the late 1980s (Chen et al., 2018). The purpose of this report technique is to estimate the two extreme conditions (e.g., trustful and distrustful conditions). More so, this technique helps to identify and understand uncertainty in decision making. Empirically, recent study found a triangular system of fuzzy information with study principals under linguistic variations (Table 3 ).

Table 3 Fuzzy number linguistic variables

\begin{tabular}{ll}
\hline Scale & Fuzzy values \\
\hline Strongly disagree & $(0,0.7,0.23)$ \\
Disagree & $(0.8,0.9,0.1)$ \\
More or less disagree & $(0.6,0.41,0.3)$ \\
Undecided & $(0.2,0.10,0.42)$ \\
More or less agree & $(0,0.77,0.71)$ \\
Agree & $(0.8,0.1,0.8)$ \\
Strongly agree & $(0.62,0.54,1)$ \\
\hline
\end{tabular}




\section{Results and discussion}

\section{Increasing green bond performance}

Using green bonds for financing purposes is a positive and cost-effective way than using traditional financing instruments or procedures. Our findings on green bonds are in line with Monk and Perkins (2020) and Maltais and Nykvist (2020). Green bonds provide an alternative way to finance with risk-free securities instead of high interest debt plans with volatile cost of equity. Thus, study findings second the arguments that green bonds are attractive financing instrument to extend green growth; as such, financing instruments are also beneficial for environmental supporting developments. To develop an attraction factor for investors with maximum access to finance is required and green bonds are most compatible to these in boosting regular bond structure, climate change mitigation, and green growth maximization (Liu et al., 2021). In other words, these investors need to strike against the bonds that hold a lower yield and align their ultimate interest with green business strategies and make their choice compatible to those with limited financing responsibilities (Tolliver, Keeley and Managi, 2020). Multidimensional environmental issues and firm financial performance nexus is an emerging challenge around the globe and is sold through green financing indicated by study findings. For green financing, green bonds are most renowned and emerging financing tools of the modern times.

These bonds are traded by different corporate stakeholders who usually ace financing constraints due to some certain reasons. In green bonds, there are few additional supportive factors for financing in comparison to conventional bonds and therefore GB is being criticized (Nguyen et al., 2021). Setting the groundwork for a large rise in energy efficiency investments in the next years would appear to be made possible by increasing economic stability, low loan rates, tax incentives, utility incentives, and higher energy costs. However, if the historic pattern holds, the capital budget will most likely reject cost-effective energy efficiency investments. Firms have for some time noticed a reluctance to invest in energy-efficient technology and refer to this as the "efficiency gap" or the "energy paradox." Basically, the bottom line is, if an investment provides more energy savings than it costs, it should be rejected. The US unmet energy efficiency potential is often estimated between 15 and $25 \%$ of the possible total (Brown et al., 2001; Bresssand et al., 2007; Ehrhardt-Martinez and Laitner, 2008). The IEA anticipated that in OECD household power, global growth in installed capacity would be around $24 \%$ by 2010 (Gueret, 2005).

Figure 2 shows green bond market structure. At the moment, the primary supply of funding for energy efficiency improvements is provided by bank loans, which have shown to be an insufficient source of capital. As an alternative to traditional loans, Energy Performance Contracts (EPC) leverage income from projects to pay back loans. Alternatively, green banks invest both public and private capital in energy efficiency. The uses for green bonds, which are issued only to finance ecologically beneficial projects or enterprises, are endless: Over the course of the year, the value of green bonds for energy efficiency increased from $\$ 16$ billion to $\$ 47$ billion (IEA 2018). A recent research issued by the IEA found that almost two-thirds of energy efficiency initiatives are paid for out of the investment firms' own coffers. However, in other cases, owners may need to get finance to get them to undertake modifications to infrastructure that will help save money on energy (USAID 2018). In the three different ways, this money is necessary; it might occur. When a business is facing a cash shortage, the first thing that must be done is to get the finances to replace outdated and inefficient equipment. A second consideration is the need of finances when planning and developing new structures. Additionally, some customers may not believe in the energy-efficiency cost reductions. Despite the financial need for better energy
Fig. 2 Green bond market structure

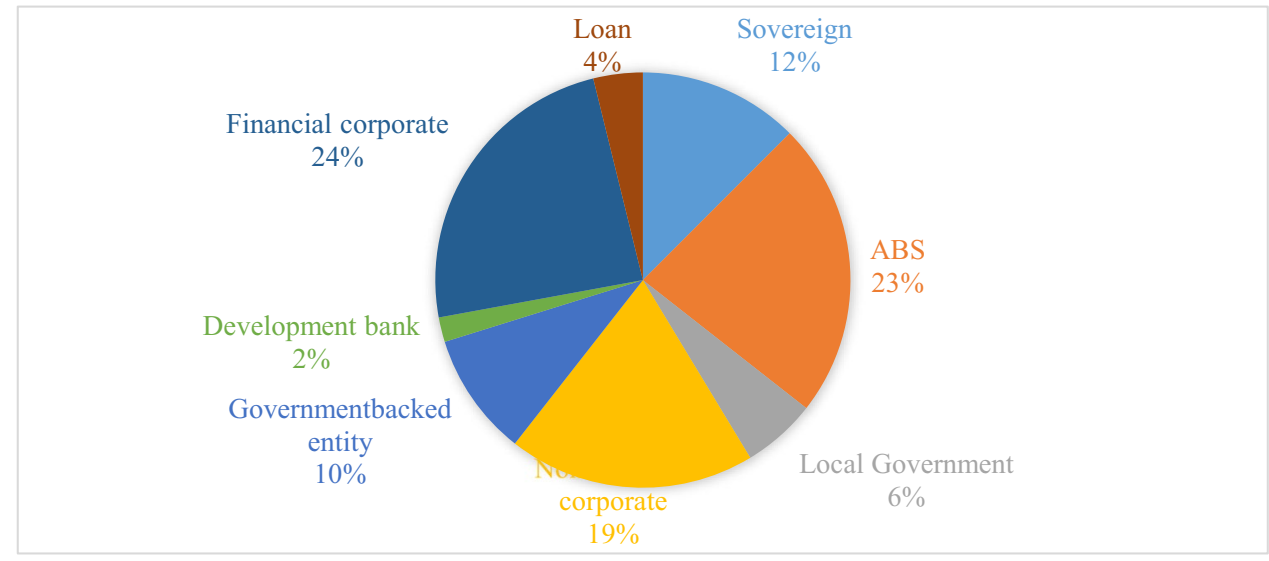


Table 4 Efficiency analysis

\begin{tabular}{ll}
\hline Type & Efficiency \\
\hline UPB & 0.72 \\
UPRB & 0.54 \\
PB & 0.61 \\
SB & 1 \\
\hline
\end{tabular}

efficiency, various roadblocks have developed (USAID 2018). Table 4 contains the effacing analysis.

There may be barriers to investing in energy efficiency owing to restricted cash or because customers and lenders are unaware of information. Access to funding for energy efficient projects is limited by liquidity restrictions, which function as a market barrier (Jones et al., 2020). When there are high collateral requirements and a limited number of energy efficiency projects, there might be a shortage of cash. Because most banks use rigorous internal credit policies that demand the availability of tangible assets as security, the majority of banks use tough internal credit rules (Reboredo, Ugolini and Aiube, 2020). Savings from energy efficiency may not be used as security for bank loans. Energy efficiency attempts in ASEAN nations are severely hampered by this factor. A normal requirement is for project customers to provide collateral equal to $80 \%$ to $120 \%$ of the project's declared volume, according to the project's risk. This means that if you get equipment to improve your energy efficiency by borrowing money from the bank, this equipment may be used as collateral. But this number fails to fulfil the $80 \%$ to $120 \%$ of project volume requirement, since it does not account for the savings that result from energy efficiency (APEC 2017).

Figure 3 shows green bond investment. Extending to it, study findings also confirmed the findings of Al Mheiri and
Nobanee (2020) that green bonds are the significant tool of financing for the climate change mitigation and to promote green economic growth in national economies. Third important issues for the green bond are green bond market globalization. Up until now, green bond market is less globalized and has limited avenues for issuance and trading; however, very limited number of buyers and seller are there who are interested in dealing with green bonds for green financing. We provide the way forward in resolving this issue of globalization through below mentioned two points,

- Boosting financing capabilities by developing financial markets structure and then by giving a platform to green bonds for efficient trading and speculation.

- Supporting low income and financially insufficient economies by allowing them to develop a refined and innovative market structure for green financing, and then by providing regulatory framework through international monetary organizations for the trading of green bonds, to generate the funds in meeting financial and economic requirements. Such emerging south economies are seriously wanting this system and around $6.5 \%$ financial support system remained supportive to such economies including Asia and Africa during 2007 to 2016 (Banga, 2019).

\section{Political distresses}

The sensible importance of green market is highlighted on the basis of above explained issues persisting with green bonds or in other words green financing as a whole, around the world. These issues tried well to highlight the importance of the green financing markets on the basis of its key drivers and antecedents, and suggested to better enhance

Fig. 3 Green bond investment

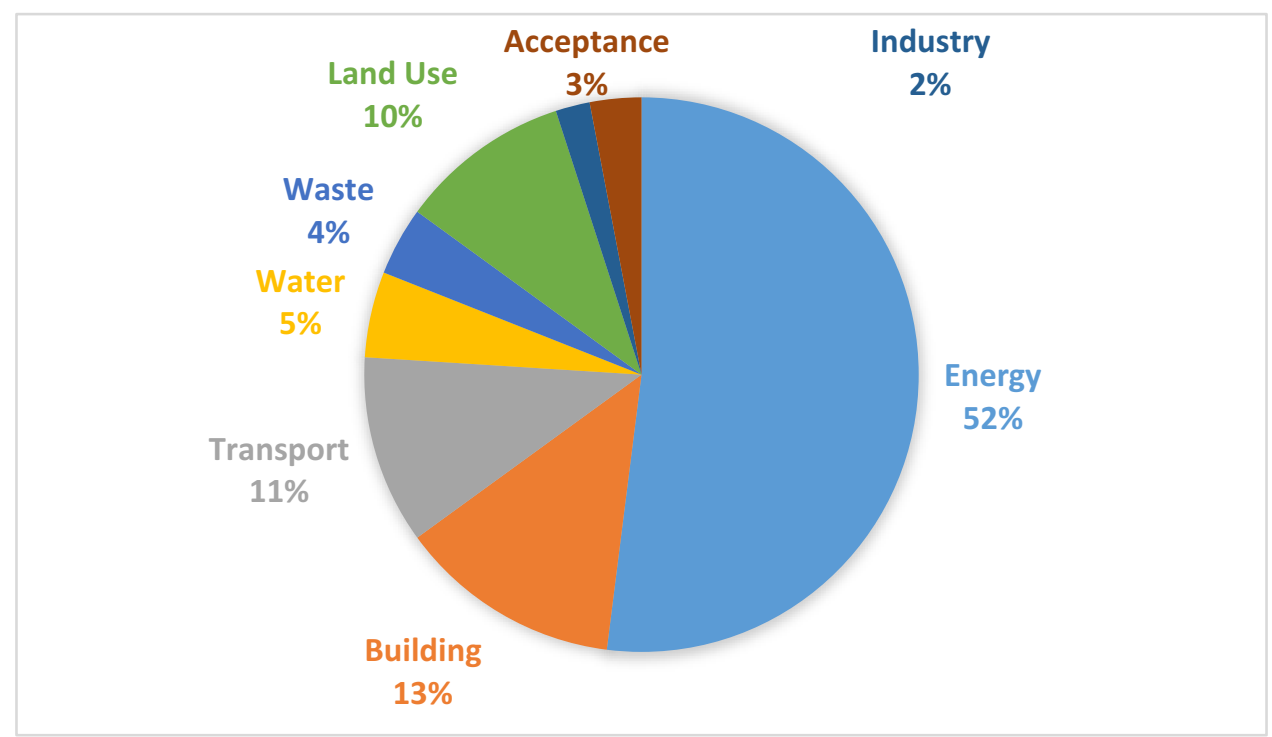


Fig. 4 Multiple barriers for green bonds to finance renewable energy solutions

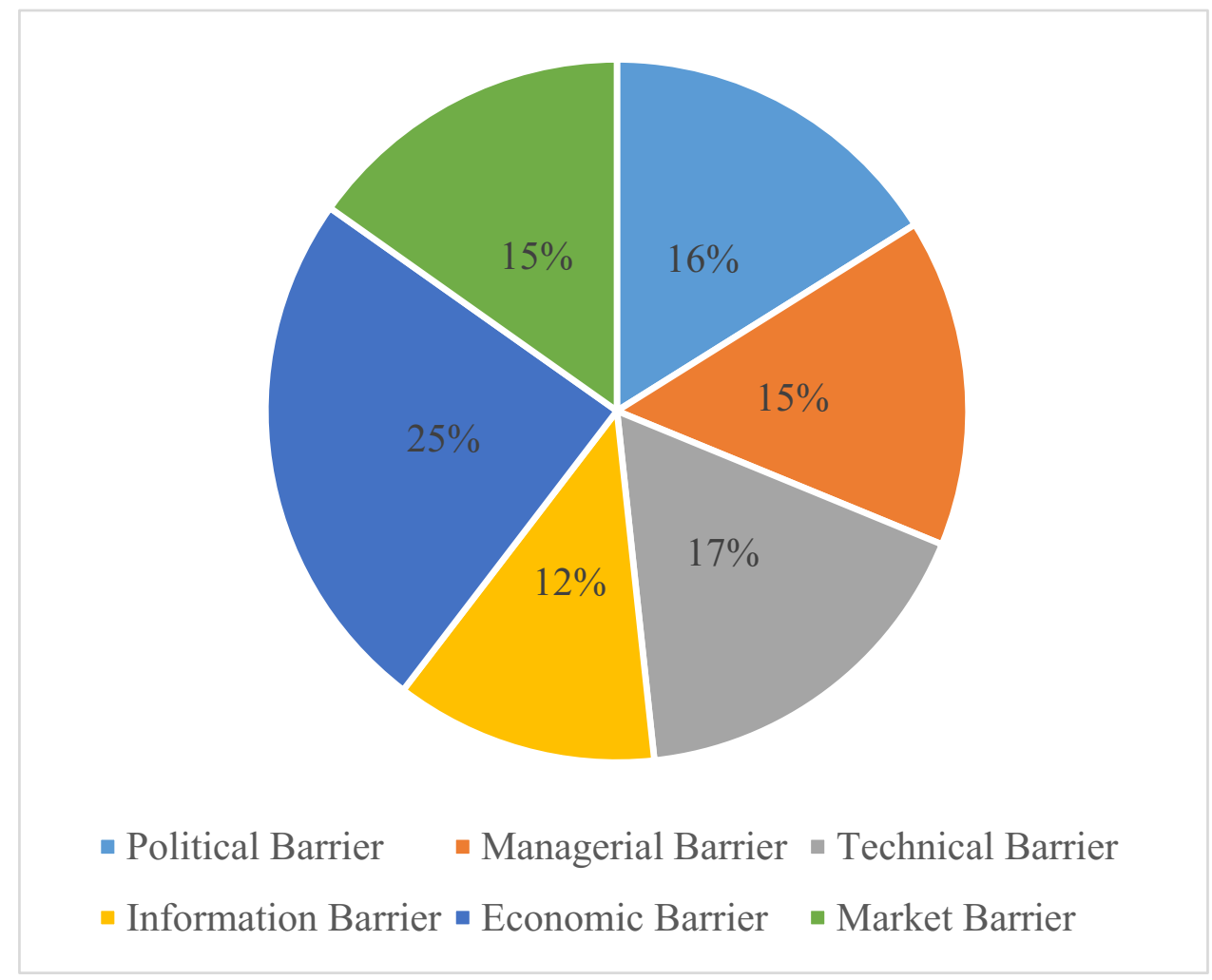

Table 5 Challenges of green innovation

\begin{tabular}{ll}
\hline Barrier & Weights \\
\hline Political barrier & 0.161 \\
Managerial barrier & 0.151 \\
Technical barrier & 0.171 \\
Information barrier & 0.121 \\
Economic barrier & 0.244 \\
Market barrier & 0.152 \\
\hline
\end{tabular}

the green bond trading structure and product profile for emerging green bond traders and investors. Despite this all, another important issue that has been less attended is the political concern of the green bonds in socio-political and green financing context. This is more broader point issue that needs discussion, as it holds the ability to enhance financial transition and economic sustainability on a greater extent. However, these persisting problems related to the green bonds for green growth acquisition are the dew drops for a novel and fresh financial management system under the concept of "going green." Therefore, recent study has given attention to this call and worked to highlight the key issues that are becoming a bunch of bigger hurdles against green bonds trading and green growth acquisition.

Figure 4 shows multiple barriers. According to the Climate Bond Initiative, the emission of labelled green bonds grew from \$41.8bn in 2015 to \$162bn in 2017 and \$167bn in
Table 6 Key drivers for green bonds promotion and green growth adoption

\begin{tabular}{llllll}
\hline & UPB & UPRB & PB & SB & Weight \\
\hline UPB & 0.53 & 0.24 & 0.46 & 0.31 & 0.33 \\
UPRB & 0.45 & 0.66 & 0.26 & 0.28 & 0.27 \\
PB & 0.29 & 0.34 & 0.37 & 0.44 & 0.49 \\
SB & 0.31 & 0.24 & 0.26 & 0.19 & 0.54 \\
\hline
\end{tabular}

2018 (CBI, 2018). However, the development of the market has been uneven over the world: the USA and the EU lead the way in the skyrocketing of emissions, and China has made speedy advances in terms of the quantity and number of emissions. Panel A in Table 5 shows evolution of green bond emissions in the EU and US green bond markets for the period 2014-2018.

\section{Fuzzy results}

With the upsurge in global population around 1.7 billion individuals, the demand for energy would massively rise revealed by the international energy agency during (IEA) 2018 conference. Several IEA agenda items revealed to reduce environmental pollution through climate change mitigation strategies for the efficient need fulfillment of energy demand. 
Fig. 5 Green bond weights

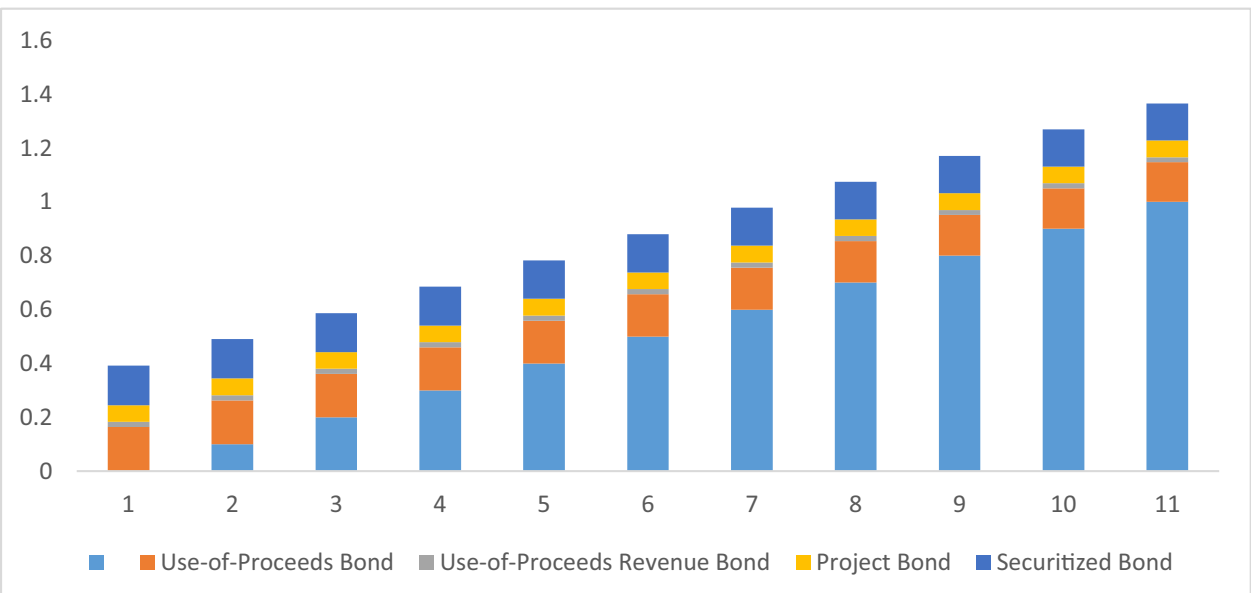

Table 7 Region-wise and currency-wise comparison of green bond market

\begin{tabular}{llll}
\hline Region & Issuers & $\begin{array}{l}\text { Green bond } \\
\text { market }\end{array}$ & Amount issued \$bn \\
\hline Africa & 11 & 4 & 2 \\
Asia-Pasific & 222 & 18 & 120 \\
Europe & 193 & 22 & 190 \\
Supernationals & 11 & - & 66 \\
Latin America & 24 & 7 & 7 \\
North America & 167 & 3 & 137 \\
Currency & & & Green bond contribution \\
UDS & & & $31 \%$ \\
EUR & & & $40 \%$ \\
Other & & & $13 \%$ \\
\hline
\end{tabular}

Results are shown in Table 6. Similarly, an induction is shown by the sustainability development scenario reducing the environmental pollution through clean and green energy around $40 \%$ until 2030. Moreover, it is expected to generate a boost in this structure through green financing and green energy until 2040 around $60 \%$. According to IEA, this would cost around 1.8 trillion US dollars. Figure 5 shows green bond weights.

\section{Use-of-proceeds bond}

UPB stands for use-of-proceeds bond, UPRB stands for use-of-proceeds revenue bond, PB stands for project bond, while SB stands for securitized bonds. The study findings also highlighted that green bonds have the greatest potential to contribute in the $\mathrm{CO}_{2}$ emission around $60 \%$ until 2050 and it would satisfy the objective to reduce global energy costs and maximize the economic growth of several economies on a greater extent. The findings further extended by confirming that green bonds contributed around $2.9 \%$ in economic welfare during last financial year of 2020, and estimates show an expected rise of $13 \%$ by the financial year of 2050 . More importantly, this welfare impact is inclined toward clean energy consumption and climate change mitigation (Table 7).

The results of study also confirmed with the policy plan of green financing, and accordingly, $\$ 400$ billion were transferred in 2020 for this intent. Moreover, this figure is upsurged toward 3 trillion US dollars by the end of financial year of 2050. A tax of $\$ 1$ per barrel would raise $\$ 7.4$ billion dollars after the first year of implementation, assuming that $50 \%$ of worldwide exports are taxed.

Figure 6 shows green bond procedure use for green growth.

Figure 7 shows green bond structure. In real terms, revenues increase gradually over time so that tax collection would amount to between \$12.9 and \$13 annual billion dollars after 20 years, depending on the value for the price elasticity of demand. On the other hand, if the tax is $\$ 5$ per barrel and only $25 \%$ of global exports are taxed, total revenue after the first year would amount to $\$ 18.4$ billion dollars. After 20 years, this figure in real terms would increase to between $\$ 31.3$ and $\$ 32.3$ annual billion dollars. The findings show the green bond market proceeds and their contribution on the bases of green bond issuers and reportings. The results designated around $38 \%$ of green bonds proceed under reporting; moreover, $79 \%$ of total amount issued with effect with $66 \%$ overall change in green growth is observed through green bonds financing. The results of the study are found consistent with previous published studied (see Ortolano and Angelini, 2021; Lebelle et al., 2020). However, study recommends to design maximum limit for financing in upcoming years and threshold limit for such financing.

Table 8 shows the sector-wise contribution of green bond financing on worldwide level which is segmented into different sectors, such as building, waste, land use, water and water-related consumption, transport and energy sector. 
Figure. 6 Green bonds proceeds use for green growth

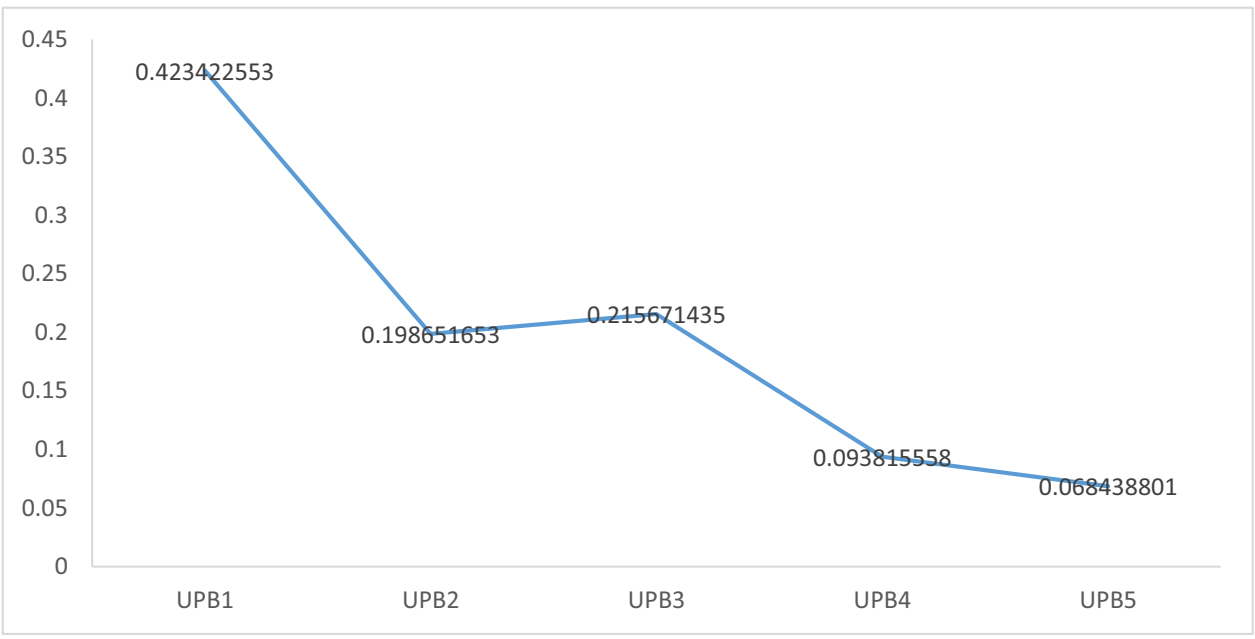

Figure. 7 Green bond structure (region-wise)

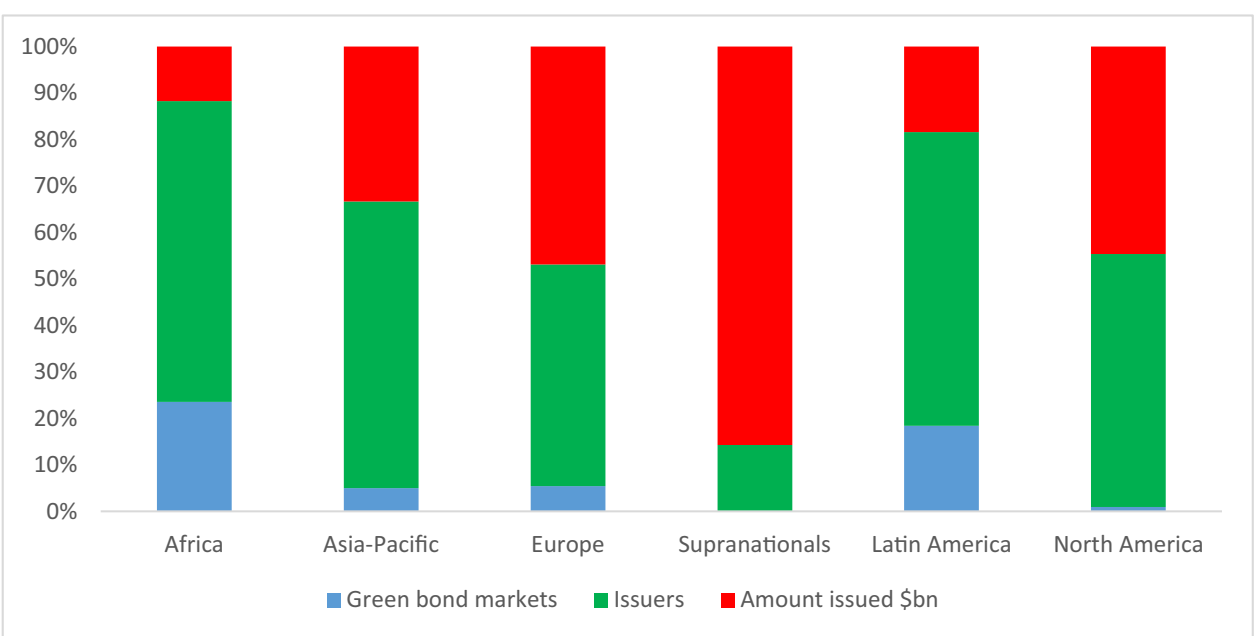

Table 8 Sector-wise contribution of green bonds in terms of USD (worldwide)

\begin{tabular}{llll}
\hline Climate-aligned & USD aligned & $\begin{array}{l}\text { \% of DM climate } \\
\text { aligned market }\end{array}$ & Climate-aligned \\
\hline Sector & Outstanding & Market & Issuers \\
Transport & $257 \mathrm{bn}$ & $53 \%$ & 64 \\
Energy & $128 \mathrm{bn}$ & $26 \%$ & 108 \\
Water & $68 \mathrm{bn}$ & $14 \%$ & 33 \\
Land use & $29 \mathrm{bn}$ & $6 \%$ & 31 \\
Waste & $4 \mathrm{bn}$ & $1 \%$ & 10 \\
Buildings & $2 \mathrm{bn}$ & $<1 \%$ & 7 \\
\hline
\end{tabular}

Correspondingly, green bonds show a wider range of financing contribution in transport sector around 53\% through 66 issuers with the net amount of 257 billion. Secondly, energy sector has more issuers (e.g., 108 individuals and organizations) in comparison to transport industry, while the financing contribution of such issuers is around $26 \%$ with the amount about 128 billion, in total. The lowest level of green bonds contribution is observed in waste sector and buildings sector, around $1 \%$ and less than $1 \%$, which needs sound focus (Fig. 8).

\section{FTOPSIS results}

Advocates of green growth naturally call on businesseslarge businesses, mainly_to adopt "green policies." While what makes a business policy "green" is usually not defined very precisely, the basic notion is that business should go beyond what is legally required to protect the environment and conserve natural resources (Table 9).

"Green" may be used to refer to more than just reducing energy usage and greenhouse gas emissions. See FurchtgottRoth (2012- same issue) for other official definitions of "green jobs." Some proponents of the so-called Porter Hypothesis (Porter and van der Linde, 1995), which holds 


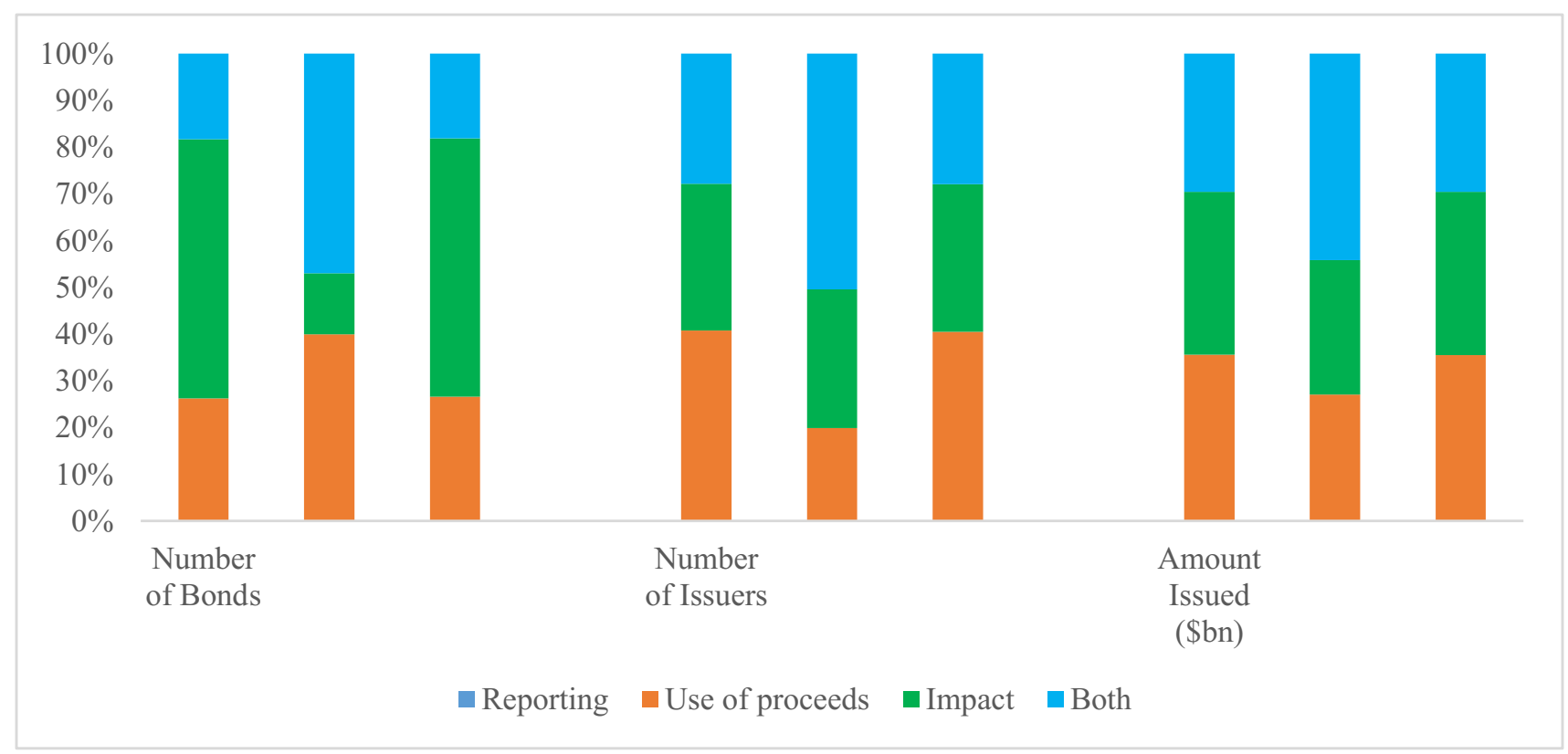

Figure. 8 Bond types and energy efficiency investment (\$bn)

Table 9 FTOPSIS findings about green bonds related to different financing issues

Table 10 Sensitivity analysis

\begin{tabular}{lllll}
\hline Green bond & $\begin{array}{l}\text { Green bond pro- } \\
\text { ceeds use }\end{array}$ & $\begin{array}{l}\text { Revenue bond } \\
\text { proceeds }\end{array}$ & Projected bonds & $\begin{array}{l}\text { Secu- } \\
\text { ritized } \\
\text { bonds }\end{array}$ \\
\hline Social acceptance & 0.33 & 0.22 & 0.15 & 0.30 \\
Political acceptance & 0.37 & 0.28 & 0.21 & 0.14 \\
Risk & 0.32 & 0.24 & 0.26 & 0.18 \\
Technological & 0.21 & 0.32 & 0.28 & 0.19 \\
\hline
\end{tabular}

\begin{tabular}{lllll}
\hline Green bond & $\begin{array}{l}\text { Green bond pro- } \\
\text { ceeds use }\end{array}$ & $\begin{array}{l}\text { Revenue bond } \\
\text { proceeds }\end{array}$ & Projected bonds & $\begin{array}{l}\text { Secu- } \\
\text { ritized } \\
\text { bonds }\end{array}$ \\
\hline Social acceptance & 0.12 & 0.08 & 0.40 & 3 \\
Political acceptance & 0.13 & 0.09 & 0.40 & 4 \\
Risk & 0.12 & 0.09 & 0.45 & 1 \\
Technological & 0.08 & 0.12 & 0.62 & 2 \\
\hline
\end{tabular}

that well-designed environmental regulation stimulates competitiveness through innovation, may argue that voluntary implementation of more stringent environmental regulations on one's own operations is often profitable (Table 10).

The "growth" component of "green growth" entails a long-term emphasis, and the starting point for conversations on long-term development strategies is sustainability (Heal, 2012). When economists evaluate the different assets a country or group of countries has, they may clarify the concept of sustainability. These are diverse sources of renewable and non-renewable natural resources, fixed capital, human health, human capital, and environmental quality. Heal (2012) considers weak sustainability to be the necessity that the future generations' stocks have a higher living standard than the ones we are passing on. As long as we continue to hold all of our stocks, reducing the value of the total portfolio is not possible. 


\section{Discussion}

Studies that concentrate on a green premium in the main GB market find a mixed, but modestly favorable, consensus. In other words, investors are ready to pay a greater price for GBs, and hence accept a lower yield. These results are relevant to issuers and the expansion of the GB market. Government entities might potentially benefit from interacting with the GB market to fund low-carbon projects at a lesser cost, notably for third-party-verified bonds. More issuers are aware of the advantages of the green premium, which is bringing growth to the GB market overall. This study suggests that future bond pricing should reflect investors' non-economic considerations, such as environmental considerations. The concept of green finance, however, is yet to reach a common agreement (Lindenberg, 2014). It can spread across areas such as green financing policies, green investments, and green financing instruments (such as green bonds). It is, therefore, timely relevant and of great interests to further explore this area, paying special attention to the transition in the energy sector, and through theoretical and empirical discussions of the current obstacles and opportunities, to find what the best possible options to policymakers. Compared to what has been raised to date by the Green Climate Fund, these are not negligible numbers.

Of course, these results would change if the assumptions on long-run trends for world GDP, oil prices and quantities were different. However, these estimates provide a rough idea of the potential from taxing crude oil exports. When it comes to combatting climate change, but also meeting the fast-expanding energy demand, mobilizing financial resources for energy efficiency initiatives is very vital. While various constraints prevent renewable energy investors from effectively courting efficiency and efficiency investments, green bonds provide a novel possibility to raise capital for projects of either kind. To attain this level, the green investment required will climb by 400 percent (DBS 2017a). This shortfall in investor assets might be filled by green bonds. Green bonds are becoming more popular. Additionally, the number of nations issuing green bonds is on the rise. The Government of Indonesia has issued around half of all green bonds in society. More than half of the money invested in green bonds is used for green buildings in various nations, while almost all of the money invested in green bonds worldwide is utilized for the production of clean energy. Malaysia and Singapore provided incentives to bond issuers to cover the expenses of third-party audits in order to make green bonds more enticing to investors. First-time issuers were more attracted to policies that support the cost of green bond issuances, and Singapore's grant programmed included a lot of first-time issuers (Chen, 2020).

Here, government policies used like these led to the issue of green bonds. To that purpose, Singapore has recently approved a 3-year grant extension for a total of six years, as well as loosened certain qualifying requirements. First-time issuers stand to benefit greatly from policies that subsidize the cost of green bond issuance. In Southeast Asian nations, the major goal of green bond funds is to stimulate green bond issuance in the nation. While it is true that the issuance of green bonds has contributed to decarbonization in the nations where these bonds were issued, this does not entail that green bond awards have really enabled decarbonization (Xu, 2020). The earnings from green bonds were also utilized to finance projects overseas or to refinance in order to pay back debts for projects already funded. To guarantee that green bond awards have a positive impact on reducing carbon emissions, countries implementing the policy should restrict the eligibility criteria to projects that are created in-country and/or need refinancing, such as Japan's green bond grant. A mixed, yet modestly favorable consensus appears among the key GB market research examining a green premium. A percentage of investors are ready to pay a greater price for GBs, and so accept a lower yield. The results are important for issuers and the expansion of the global GB market. Government organizations with third-party verification of bond revenues may benefit from interacting with the GB market, which allows them to fund low-carbon activities at a lesser cost. If issuers continue to discover the revenue advantages of offering a green premium, the GB market will see further expansion. This new study suggests that bond pricing theory should incorporate the investors' non-economic considerations, such as environmental considerations (Sahana et al., 2021).

\section{Conclusion and policy implication}

We use F-TOPSIS to assess barriers to Yemeni renewable energy projects. The Yemeni renewable energy industry will remain unchanged until green innovation approaches are applied. Renewable energy industry has slowed owing to insufficient capacity-based scale. While the political barrier weighs in at 0.191 , the technical barrier weighs in at 0.181 . Information and management energy levels are determined to be 0.17 and 0.18 , respectively. The market barrier weighs 0.12 , whereas the economic barrier weighs 0.15 . We urgently need to launch the country's renewable energy programmed. Study gives the following policy implications:

a) Government should introduce awareness program for installation renewable projects.

b) Policymakers should introduce public-private partnership programs.

c) Subsidy should be implemented for renewable energy and simultaneously tax should be imposed for fossil fuel.

The concept of green finance, however, is yet to reach a common agreement (Zhou et al., 2020). It can spread across areas such as green financing policies, green investments, and green financing instruments, such as green bonds. It is, 
therefore, timely relevant and of great interests to further explore this area, paying special attention to the transition in the energy sector, and through theoretical and empirical discussions of the current obstacles and opportunities, to find what the best possible options to policymakers.

Providing for screening energy efficiency investment proposals with small payback hurdle rates might have large opportunity costs. Rules-of-thumb are created using "worst-case" assumptions, meaning many investments the business may have thought successful would be eliminated. Value-at-Risk is defined and a new application called Energy Budgets at Risk $(\mathrm{EBaR})$ is provided for building efficiency project risk and return analysis for financial decision-makers. An example project used the EBaR method to illustrate the benefit of both risk analysis and typical engineering project reports. The paper recommends incorporating Value-at-Risk-type energy efficiency analysis in utility, state, and federal incentive programs and in government energy efficiency projects, through professional organizations, licensing requirements, and other means.

Author contribution Write up corrections, data curation, supervision: Yiyi Ning, Jacob Cherian, Muhammad Safdar Sial, and Susana Álvarez-Otero; visualization, editing, writing of draft: Yiyi Ning, Jacob Cherian, Muhammad Safdar Sial, and Susana Álvarez-Otero; writing and software: Ubaldo Comite, Mohammed Arshad Khan, and Malik Zia-Ud-Din; writing, editing, and visualization: Yiyi Ning, Jacob Cherian, Muhammad Safdar Sial, and Susana Álvarez-Otero; conceptualization, methodology: Ubaldo Comite, Mohammed Arshad Khan, and Malik Zia-Ud-Din; review, visualization: Ubaldo Comite, Mohammed Arshad Khan, and Malik Zia-Ud-Din.

Data Availability Data is publicly available at mentioned sources in data section.

\section{Declarations}

Ethical approval and consent to participate We declare that we have no human participants, human data, or human issues.

Competing interests The authors declare no competing interests.

Consent for publication We do not have any individual person's data in any form and we give consent for publication in true letter and spirit.

\section{References}

Al Mheiri, W., \& Nobanee, H. (2020). Green Bonds: A MiniReview. Available at SSRN 3538790.

Alemzero DA, Iqbal N, Iqbal S, Mohsin M, Chukwuma NJ, Shah BA (2021) Assessing the perceived impact of exploration and production of hydrocarbons on households perspective of environmental regulation in Ghana. Environ Sci Pollut Res 28(5):5359-5371

Anh Tu, C., Chien, F., Hussein, M. A., Ramli MM, Y., Psi MM, M. S. S., Iqbal, S., \& Bilal, A. R. (2021). Estimating role of green financing on energy security, economic and environmental integration of BRI member countries. The Singapore Econ Rev
Azhgaliyeva D, Kapoor A, Liu Y (2020) Green bonds for financing renewable energy and energy efficiency in South-East Asia: a review of policies. J Sustain Finance Invest 10(2):113-140

Barua S, Chiesa M (2019) Sustainable financing practices through green bonds: What affects the funding size? Bus Strateg Environ 28(6):1131-1147

Boran K (2017) An evaluation of power plants in Turkey: Fuzzy TOPSIS method. Energy Sources Part B 12(2):119-125

Bracking S (2015) Performativity in the Green Economy: how far does climate finance create a fictive economy? Third World Quarterly 36(12):2337-2357

Browne S (1995) Optimal investment policies for a firm with a random risk process: exponential utility and minimizing the probability of ruin. Math Oper Res 20(4):937-958

Chen J (2020) Risk assessment algorithm for agricultural value chain financing in coastal areas based on HMM model. J Coast Res 103(sp1):42. https://doi.org/10.2112/SI103-010.1

Chen W, Shen Y, Wang Y (2018) Evaluation of economic transformation and upgrading of resource-based cities in Shaanxi province based on an improved TOPSIS method. Sustain Cities Soc 37:232-240

Chugan, P. K., Mungra, Y., \& Mehta, K. (2017). Challenges and policy implications for marketing green bonds. Book titled" Consumer Behaviour \& Contemporary Marketing Strategy",(Eds.), Tripurasundari Joshi, Jayesh P. Aagja and Sapna Parashar, Excel India Publishers, New Delhi for IMNU, 371-384.

Devine, A., \& McCollum, M. (2021). Advancing energy efficiency through green bond policies. Available at SSRN 3856312.

Draksaite, A., Kazlauskiene, V., \& Melnyk, L. (2018). The perspective of the green bonds as novel debt instruments in sustainable economy. In Consumer Behavior, Org Strat Financ Econ (pp. 221-230). Springer, Cham.

Durrani A, Rosmin M, Volz U (2020) The role of central banks in scaling up sustainable finance-what do monetary authorities in the Asia-Pacific region think? J Sustain Finance Invest 10(2):92-112

Flammer, C. (2021). Corporate green bonds. J Financ Econ

Gao H, Shi D, Zhao B (2021) Does good luck make people overconfident? Evidence from a natural experiment in the stock market. J Corp Finan 68:101933. https://doi.org/10.1016/j.jcorpfin.2021. 101933

Gianfrate G, Peri M (2019) The green advantage: exploring the convenience of issuing green bonds. J Clean Prod 219:127-135

Gibon, T., Popescu, I. S.., Hitaj, C., Petucco, C., \& Benetto, E. (2020). Shades of green: life cycle assessment of renewable energy projects financed through green bonds. Environ Res Lett 15(10), 104045.

Special Issue in" Green and Sustainable Finance" https://www.mdpi. com/journal/jrfm/special_issues/GSF. Accessed 12 September 2021.

Iqbal S, Bilal AR, Nurunnabi M, Iqbal W, Alfakhri Y, Iqbal N (2021a) It is time to control the worst: testing COVID-19 outbreak, energy consumption and CO 2 emission. Environ Sci Pollut Res 28(15):19008-19020

Iqbal, S., Taghizadeh-Hesary, F., Mohsin, M., \& Iqbal, W. (2021). Assessing the role of the green finance index in environmental pollution reduction. Stud Appl Econ 39(3).

Jones R, Baker T, Huet K, Murphy L, Lewis N (2020) Treating ecological deficit with debt: the practical and political concerns with green bonds. Geoforum 114:49-58

Le TH, Chang Y, Taghizadeh-Hesary F, Yoshino N (2019) Energy insecurity in Asia: a multi-dimensional analysis. Econ Model 83:84-95

Lebelle M, Lajili Jarjir S, Sassi S (2020) Corporate green bond issuances: an international evidence. J Risk Financ Manag 13(2):25

Li, W., Chien, F., Hsu, C. C., Zhang, Y., Nawaz, M. A., Iqbal, S., \& Mohsin, M. (2021). Nexus between energy poverty and energy 
efficiency: estimating the long-run dynamics. Resour Policy, 72, 102063.

Linton S, Clarke A, Tozer L (2021) Strategies and governance for implementing deep decarbonization plans at the local level. Sustainability 13(1):154

Liu, N., Liu, C., Da, B., Zhang, T., \& Guan, F. (2021). Dependence and risk spillovers between green bonds and clean energy markets. J Clean Prod, 279, 123595.

Maltais, A., \& Nykvist, B. (2020). Understanding the role of green bonds in advancing sustainability. J Sustain Finance Invest, 1-20.

Mohsin M, Abbas Q, Zhang J, Ikram M, Iqbal N (2019) Integrated effect of energy consumption, economic development, and population growth on $\mathrm{CO} 2$ based environmental degradation: a case of transport sector. Environ Sci Pollut Res 26(32):32824-32835

Monk, A., \& Perkins, R. (2020). What explains the emergence and diffusion of green bonds?. Energy Policy, 145, 111641.

Nelson RR, Winter SG (1982) The Schumpeterian tradeoff revisited. Am Econ Rev 72(1):114-132

Nenonen, S., Koski, A., Lassila, A. P., \& Lehikoinen, S. (2019, October). Towards low carbon economy-green bond and asset development. In IOP Conference Series: Earth Environ Sci (Vol. 352, No. 1, p. 012028). IOP Publishing.

Nguyen, T. T. H., Naeem, M. A., Balli, F., Balli, H. O., \& Vo, X. V. (2021). Time-frequency comovement among green bonds, stocks, commodities, clean energy, and conventional bonds. Finance Res Lett $40,101739$.

Ortolano, A., \& Angelini, E. (2021). Green bonds capital returns: the impact of market and macroeconomic variables. Contemporary Issues in Sustainable Finance: Financ Prod Financ Inst 91.

Reboredo, J. C., Ugolini, A., \& Aiube, F. A. L. (2020). Network connectedness of green bonds and asset classes. Energy Econ, 86, 104629.

Russo A, Mariani M, Caragnano A (2021) Exploring the determinants of green bond issuance: going beyond the long-lasting debate on performance consequences. Bus Strateg Environ 30(1):38-59

Sachs, J. D., Woo, W. T., Yoshino, N., \& Taghizadeh-Hesary, F. (2019). Why is green finance important?.

Sahana M, Rehman S, Paul AK, Sajjad H (2021) Assessing socio-economic vulnerability to climate change-induced disasters: evidence from Sundarban Biosphere Reserve, India. Geol Ecol Landsc 5(1):40-52. https://doi.org/10.1080/24749508.2019.1700670
Taghizadeh-Hesary F, Yoshino N (2019) The way to induce private participation in green finance and investment. Financ Res Lett 31:98-103

Taghizadeh-Hesary F, Rasoulinezhad E, Yoshino N (2019) Energy and food security: linkages through price volatility. Energy Policy 128:796-806

Tang, D. Y., \& Zhang, Y. (2020). Do shareholders benefit from green bonds?. J Corp Finance, 61, 101427.

Tolliver, C., Keeley, A. R., \& Managi, S. (2020). Policy targets behind green bonds for renewable energy: Do climate commitments matter?. Technol Forecasting Social Change, 157, 120051.

Tu, C. A., Rasoulinezhad, E., \& Sarker, T. (2020). Investigating solutions for the development of a green bond market: Evidence from analytic hierarchy process. Finance Res Lett, 34, 101457.

Wiśniewski M, Zieliński J (2019) Green bonds as an innovative sovereign financial instrument. Ekonomia i Prawo Econ Law 18(1):83-96

Xin-tu, Lei Qing-yuan, Xu Cheng-ze, Jin Nature of property right and the motives for holding cash: Empirical evidence from Chinese listed companies. Managerial and Decision Economics. https:// doi.org/10.1002/mde.3469

Xu X (2020) Warehousing Financing Behavior of Global Logistics System under the Situation of Financial Crisis. J Coast Res 103(sp1):658. https://doi.org/10.2112/SI103-134.1

Yoshino N, Taghizadeh-Hesary F, Nakahigashi M (2019) Modelling the social funding and spill-over tax for addressing the green energy financing gap. Econ Model 77:34-41

Yoshino, N., Taghizadeh-Hesary, F., \& Otsuka, M. (2021). Covid19 and optimal portfolio selection for investment in sustainable development goals. Finance Res Lett, 38, 101695.

Zhou X, Cui Y (2019) Green bonds, corporate performance, and corporate social responsibility. Sustainability 11(23):6881

Zhou X, Tang X, Zhang R (2020) Impact of green finance on economic development and environmental quality: a study based on provincial panel data from China. Environ Sci Pollut Res 27(16):19915-19932

Publisher's note Springer Nature remains neutral with regard to jurisdictional claims in published maps and institutional affiliations. 